\title{
Analysis of the Processes of Gravity in the Framework of Curvature of Space and the Substantiation of the New Model
}

\author{
Valentyn Nastasenko \\ Kherson State Maritime Academy, Kherson, Ukraine \\ Email: nastasenko2004@ukr.net
}

How to cite this paper: Nastasenko, V. (2020) Analysis of the Processes of Gravity in the Framework of Curvature of Space and the Substantiation of the New Model. Journal of Applied Mathematics and Physics, 8, 2732-2743.

https://doi.org/10.4236/jamp.2020.812202

Received: October 23, 2020

Accepted: December 1, 2020

Published: December 4, 2020

Copyright $\odot 2020$ by author(s) and Scientific Research Publishing Inc. This work is licensed under the Creative Commons Attribution International License (CC BY 4.0).

http://creativecommons.org/licenses/by/4.0/

\begin{abstract}
The paper belongs to the sphere of quantum physics, physics of waves and physical fields, in particular-to the gravitation. Their study provides a better understanding of the problems of natural sciences at all levels, from elementary particles, to Universe as a whole. Therefore, the solution of these problems is an urgent and important task, which to the works of many generations of scientists of the world was dedicated. However, they have not been fully resolved. In well-known works, including general relativity, determination of the wave and energy parameters of the gravitational field of the Universe and their numerical values are absent. Solutions found are limited to tensor equations of a general form, which allows their interpretation of over a wide range. Other disadvantages of famous models are: 1) the voluminous world of the Universe reduced to the planes on which space objects and other objects move, sagging planes due to their own mass; 2) signs of "top" and "bottom" of the system, which are not in the real Universe, just as they are not on Earth and not in the Solar system; 3) the formation of "voids" between the object and the curved space and others. Main goals of the work to identify these contradictions and find ways to resolve them are performed. The main difference and the scientific novelty of the work performed are the justification of the gravity model based on a rigorous determination of the wave and energy parameters of the gravitational field of the Universe and their numerical values. The initial parameters of this worked-is the frequency oscillation $v_{G}$ of the waves of the gravitational field (Nastasenko's constant) found in 2011. Research Results: Knowing $v_{G}$ can find all wave parameters of the gravitational field and their numerical values. The proposed new spatial-wave model of the action of gravity is based on the wave parameters of the gravitational fields of material objects. In the framework of their unity with electromagnetic fields, it reduces their structures to similar ones and eliminates the
\end{abstract}


drawbacks of the previous model—of replaced gravity on curvature of space.

\section{Keywords}

Gravity, Curvature of Space, Gravitational Field, Space-Wave Model of Gravity

\section{Introduction}

Gravity is associated with the foundations of the material world and with the entire Universe; its study provides a better understanding of the problems of natural sciences at all levels, from elementary particles, atoms and molecules, to macro and mega levels-planets, stars, their systems, galaxies and the Universe as a whole. Therefore, the solution of these problems is an urgent and important task, which to the works of many generations of scientists of the world was dedicated, from the time of ancient civilizations to the present [1] [2] [3]. However, they have not been fully resolved, which requires the elimination of this drawback.

Currently, the questions of formation of gravity and the gravitational field are not well studied. Although the basic provisions of the gravitation theory were developed by Einstein in the general theory of relativity (GRT) [4], however, they were found on the basis of several axioms, the main of which are: replacing gravitation with the curvature of space, of zero photon mass, etc.

Such a replacement was not accepted by the entire scientific community, so Einstein received the Nobel Prize in Physics not for GRT, but for explaining the photoelectric effect. In the 20s of the XX century, the principles of relativity in [5] came out in the first place, and GRT has been widely recognized. The second part of the work-the curvature of space-has been also gradually recognized [6], and on this basis a large number of doctoral dissertations were defended, although criticism of the Einstein axioms continued. However, scientists who defended such doctoral dissertations, allowing them to receive high ranks and positions, began to dominate the scientific world and suppress this criticism, which is confirmed by the difficulties with the publication of this article in other scientific journals. Since truth is born only in honest debate, this article is the second attempt at such a debate. The first attempt is presented in [7].

Analysis of physical and mathematical models [4] [5] [6], explaining the axiom of curvature of space, showed that they have a number of inaccuracies and contradictions [7], which requires further detailed processing. Identifying these contradictions and finding ways to resolve them are the main goals of the work performed.

The second goal of the work is the analysis of modern achievements in the field of studying gravity and the ways of their development, which should be taken into account in further scientific research and in the teaching of physics disciplines in higher educational institutions, as well as adapted-in secondary 
specialized educational institutions and schools.

The implementation of these goals is justified by recent scientific knowledge gained in the field of studying the gravitational field: 1) the discovery of the existence of gravitational waves (without determining their wave parameters), which was awarded the 2017 Nobel Prize in Physics [8]; 2) a rigorous justification of the wave parameters of the gravitational field [9] [10] [11]. Recent works are little known to scientists and working in this field teachers, which reduces the further level of development of science and the training of scientists, specialists and teachers. Therefore, it is required to eliminate the indicated disadvantage.

\section{Working Methods}

The performed work is based on the methods of deduction and induction in the research of the material world based on the application of the well-known reliable laws of physics and the general principles of the development of the theory of knowledge. Other research methods are still unknown, since the work performed is associated with new scientific discoveries, the search for which is difficult to formalize by technique methods.

The main difference and the scientific novelty of the work performed is the justification of the gravity model based on a rigorous determination of the wave and energy parameters of the gravitational field of the Universe and their numerical values. In well-known works, including general relativity, such information and numerical values are absent, and the solutions found are limited to general equations [3] [4] [5] [6] [7], which allows their variation. At the same time, the replacement of gravity with space curvature is an axiom for which neither Einstein himself nor other scientists of the world have brought rigorous physical evidence, except for a number of abstract tensor mathematical dependencies [3] [4] [5] [6]. This drawback is indicated in the article [7]. As a result, the voluminous world of the Universe was reduced to the planes on which space objects and other objects move, sagging planes due to their own mass. The physical and mathematical models of such states of bodies and surfaces bent by them are shown in Figure 1.

\section{Results and Its Discussion}

The research process is to identify the shortcomings of the known model of gravity and correcting them in the new proposed model.

The physical model (Figure 1(a)) cannot be a justification for Einstein axiom, since it actually explains only the state of the elastic membrane under the action of 1 spherical object located on it and some possibilities of its interaction with other objects. And no more than that! The model cannot provide a stable location and movement of the 2 nd object relative to the 1st, they merge. Wherein, the membrane is not necessarily equatorial, as in the mathematical model shown in Figure 1(b). These models have nothing to do with the volumetric space of 


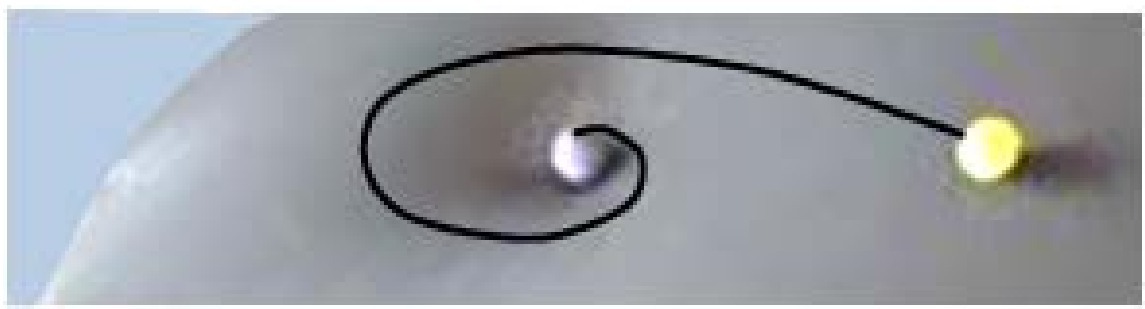

(a)

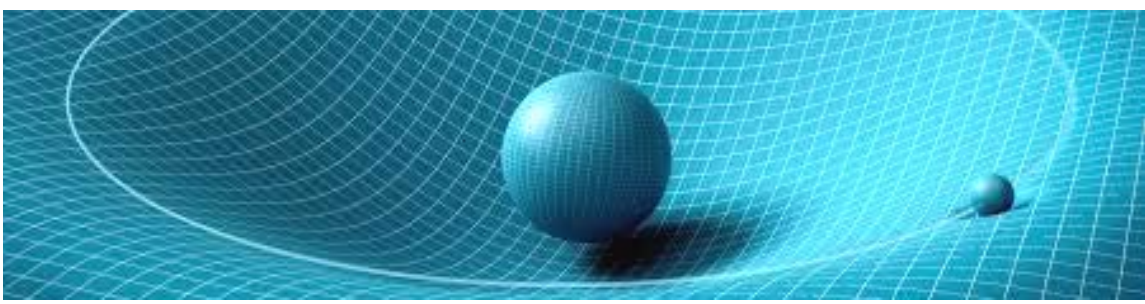

(b)

Figure 1. Physical (a) and mathematical (b) models of the curvature of space (hereinafter, we use pictures from the website.

https://ru.depositphotos.com/stock-photos/\%D0\%B3\%D1\%80\%D0\%B0\%D0\%B2\%D0\%B 8\%D1\%82\%D0\%B0\%D1\%86\%D0\%B8\%D1\%8F.html).

the Universe, since it is not clear from them how space behaves above and below the membrane and in the voids between the object and the curved layer (Figure 1(b) and Figure 2) [7]. At the same time, the voids in the models are different-in the previous one-before the orbit of the moon, in the second-in the satellite flight zone, which indicates the arbitrariness of their construction, as the developer wants.

There were no such voids in previous models in them the curvature of space is associated with the object itself (Figure 3(a)) [12] [13], which did not deprive these models of other shortcomings. With a common initial curvature surface (Figure 3(b)), the mutual arrangement of a system of objects with different masses and space deflections does not allow them to be located in a common orbital plane, which contradicts the interaction of Earth-Moon systems. Therefore, the previous model Figure 3(a) was replaced by new ones: Figure 1(b) and Figure 2).

The need to switch from a flat model to a bulk one will require at least several layers of such elastic membranes with their variants of curvature, which significantly complicates the scheme of their general interaction, shown in Figure 1(b) and Figure 2. In this case, of the development of a new computer model not only technical difficulties arise, but also a number of other problems of fundamental importance:

1) There are signs of "top" and "bottom" of the system, which are not in the real Universe, just as they are not on Earth and not in the Solar system [2] [7].

2) The scheme of gravity and transformation of the space of the upper part of the object is absent, which exist but in space is not stretched further.

3) It is unclear how the satellite shown in the diagram Figure 2 affected the space. 


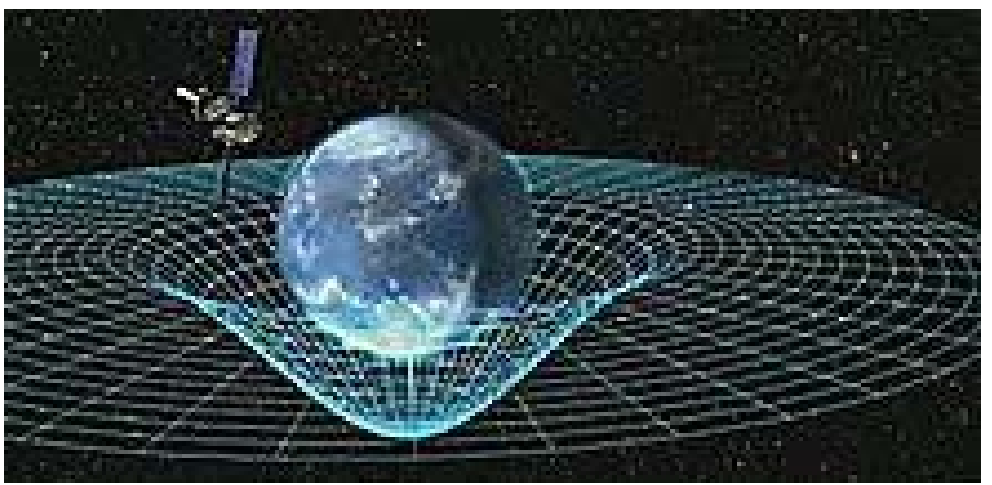

Figure 2. The modern model of the curvature of space by the mass of the object.

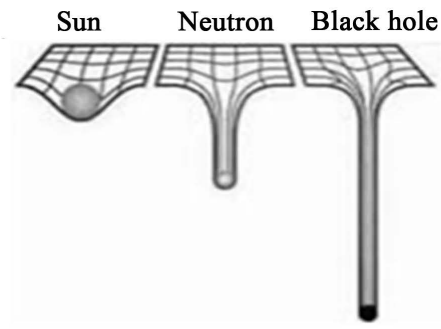

(a) curvature of the common space for objects with different masses

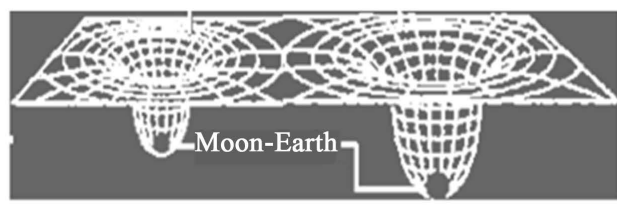

(b)

Figure 3. Mathematical models of the curvature of space, tied to objects (a) that lead to a mismatch of the orbits of the Earth and the Moon (b).

4) The space in the void near the object is absent? Where does this space disappear? Therefore, such voids cannot be in principle, they are filled either with the original space or with some other space that needs to be justified [7].

5) The formation of voids or other space that fills them requires real physical processes of their appearance and further stable support [7].

6) If the void between the equatorial membrane and the object is filled with layers from the upper part of the object, then they should have a smooth transition, so the upper layers of the membranes will stretch and the lower ones will shrink, filling the voids [7]. Therefore requires physical processes for such metamorphoses and their explanation, taking into account the energy costs of such deformations.

7) Compression and stretching of the membrane layers will create a no equilibrium state, which, within the framework of the laws of entropy, will tend to go into equilibrium [7]. Violation of the laws of entropy in the Universe is also an axiom [14], which can be excluded, of the used hypothesis of replenishing the Universe with external energy. This hypothesis has the same right to exist as the hypothesis of the Big Bang of the Universe.

8) When developing mathematical models, it must be taken into account that space is well bent, stretched and compressed in mathematical formulas with an infinite decrease in its parameters. However within the framework of physical reality with finite parameters of a space quantum and the not possibility of its deformation [15] [16], all mathematical dependencies will be different, which 
requires the processing of the calculation formulas of these models and a number of GR provisions.

9) If we take into account the incompressibility of the final form of the minimum quanta of the space of the Universe, less than which nothing can be [15] [16], then quanta will discretely form (for example from of small cubes) spherical layers with different gravity from an object located in space. However the numbers of such quanta in the zone of this object will decrease or be absorbed by it (Figure 4), that requires an explanation of the physical foundations of these processes. This proposed model contains 2 variants of quanta: hard (for example cubes) and curved (for example segments).

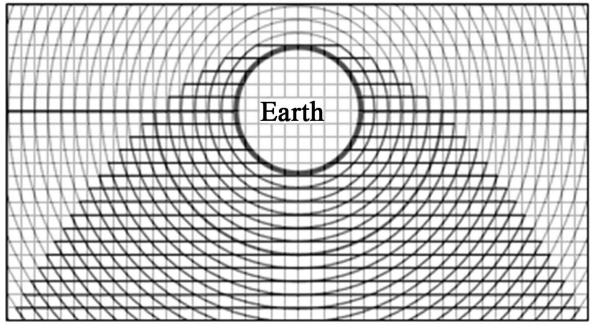

Figure 4. Transformation of the initial quanta into quanta of curved space with the equatorial zone of the object (the scheme of the author of this work).

The construction of the model based on hard quanta of space eliminates the disadvantages indicated in paragraphs 4 - 9; therefore it is more appropriate. However, such a model does not eliminate the drawbacks indicated in paragraphs 1 - 3. In addition, it must be explained why the original space penetrates or is absorbed by the space of another object, since within the framework of the general principles of their interaction, the object occupies or replaces the original space.

It should be noted that when correcting the elastic properties of the membrane at all its points, the effect of dividing objects into stable orbits of their motion will be possible, but such a mathematical model and its description will become very complicated. This factor can be taken into account in the development of future programs for PCs, but there is no clarity as to why and how it is implemented in reality. In addition, for the model shown in Figure 1(b), there is no clarity of the interaction of the membrane layers with other objects if their number is more than 1 (Figure 5), and their orbits will be located in different planes relative to the base object (for example this is how its artificial satellites fly around the Earth).

Only objects with a high speed of motion can slip out of the dent of space from a massive object, wherein they curvature their paths (Figure 6(a)). Such curvature of photon's trajectory (within the framework of the axiom of its zero mass, which excludes the action of gravitational forces on it according to Newton's law of universal gravitation), was calculated by Einstein in 1915. It is believed that this work received experimental validation during the Solar Eclipse of 1919 when observing the light of a star (Figure 6(b)) [17]. 


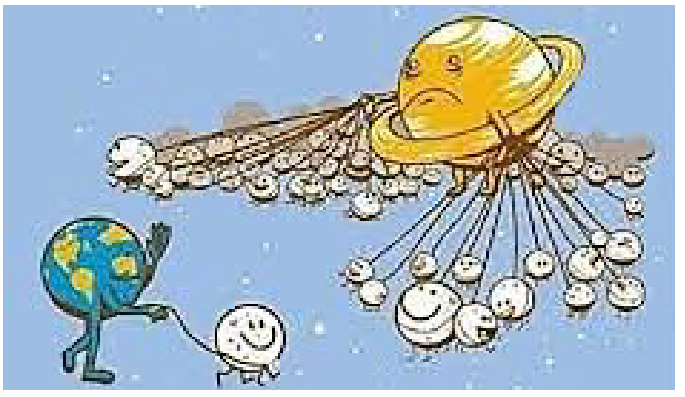

Figure 5. Comic scheme of interaction of space objects with one and with a large number of satellites.

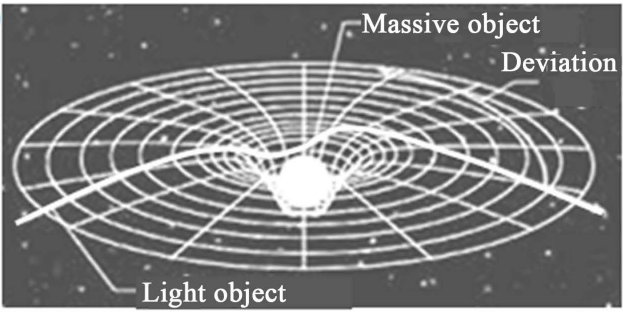

(a)

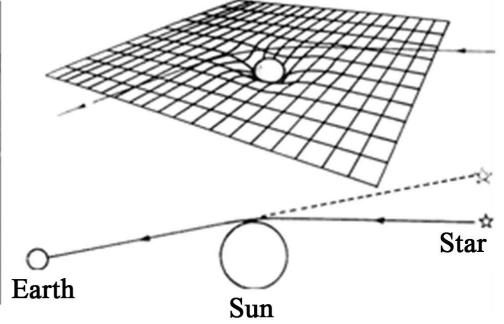

(b)

Figure 6. Scheme of movement of a light object near a massive (a); and the scheme of the passage of light rays from a distant star near the Sun (b).

The coincidence of these calculated data with experimental measurements served as the basis for the recognition of general relativity in the scientific world [17].

Thus, we can conclude that for a variety of objects of the Universe a single plane-membrane does not exist. In principle, it is possible to create such physical and mathematical models, however how in the real Universe unstable states are created and held, caused by compaction and expansion of space in the known models; it is difficult to explain without an external supply of energy. The source of its appearance is also unclear, and the problems of implementing these processes for a huge number of stars and other objects of the Universe contradict the principles of minimizing transformations and performed actions, which confirms, for example, the Pauli principle for the formation of atomic orbits [18]. Even allowing the thought of the creation of the Universe by the omnipotent Divine mind, its infinite energy and possibilities [19], the playful question arises, why does God need such a "thorn in his side"?

Modern research in the field of gravity [7] [9] [10] [11] allows us to eliminate these disadvantages. For example, the problem of "top" and "bottom" can be eliminated if "bottom" is associated with the attraction of the Sun. However, in the models shown in Figure 1(b), Figure 2, Figure 3, the Sun is not "bottom", his located on the "side". Therefore, these models all need to be redone.

A more complete way of eliminating the shortcomings identified above is associated with the new model. In which the initial is the oscillation frequency $v_{G}$ of the wave of the gravitational field, discovered in 2011 [9] (Nastasenko con- 
stant [11]). She was obtained on the basis of the strict physical dependence (1), which consists of 3 fundamental physical constants: speed $c$ of light in vacuum, gravitational constant $G$ and Planck constant $h$, the numerical values of which are recommended by CODATA [20]:

$$
\begin{aligned}
v_{G} & =\sqrt{\frac{c^{5}}{G h}}=\sqrt{\frac{\left[0.299792458 \times 10^{9}\left(\frac{\mathrm{m}}{\mathrm{s}}\right)\right]^{5}}{6.67408 \times 10^{-11}\left(\frac{\mathrm{m}^{3}}{\mathrm{~kg} \cdot \mathrm{s}^{2}}\right) \times 6.626070040 \times 10^{-34}\left(\frac{\mathrm{kg} \cdot \mathrm{m}^{2}}{\mathrm{~s}}\right)}} \\
& =7.39994 \times 10^{42}\left(\mathrm{~s}^{-1}\right) \rightarrow 7.4 \times 10^{42}\left(\mathrm{~s}^{-1}\right)
\end{aligned}
$$

The presence of waves of the gravitational field (without its parameters) was confirmed experimentally (Nobel Prize in Physics 2017) [8]. Knowing $v_{G}$ can find other wave parameters of the gravitational field and their numerical values [9] [10] [11]:

Period of oscillation $T_{G}$ :

$$
T_{G}=\frac{1}{v_{G}}=\frac{1}{7.4 \times 10^{42}\left(\mathrm{~s}^{-1}\right)}=0.135135135135 \cdots \times 10^{-42}=0 .|135| \times 10^{-42}(\mathrm{~s})
$$

Length of carrier wave $\lambda_{G}$ :

$$
\lambda_{G}=\frac{c}{v_{G}}=\frac{0.299792458 \times 10^{9}\left(\frac{\mathrm{m}}{\mathrm{s}}\right)}{7.4 \times 10^{42}\left(\mathrm{~s}^{-1}\right)}=4.051249|432| \times 10^{-35}(\mathrm{~m})
$$

Amplitude of oscillation $A_{G}$ :

$$
A_{G}=\lambda_{G}=4.051249|432| \times 10^{-35}(\mathrm{~m})
$$

Wave energy $E_{G}$ its maximum quantum of energy:

$$
\begin{aligned}
E_{G} & =h v_{G}=6.626070040 \times 10^{-34}(\mathrm{~J} \cdot \mathrm{s}) \times 7.4 \times 10^{42}\left(\mathrm{~s}^{-1}\right) \\
& =4.9032918286 \times 10^{9}(\mathrm{~J})
\end{aligned}
$$

Mass equivalent $m_{G}$ of the wave energy $E_{G}(5)$ of the gravitational field, or its energy mass, which in the framework of Plank's law energy $E_{G}=h v_{G}$ and Einstein's law $E_{G}=m_{G} c^{2}$ on the connection of total energy and mass.

$$
\begin{aligned}
m_{G} & =\frac{E_{G}}{c^{2}}=\frac{h v_{G}}{c^{2}}=\frac{6.626070040 \times 10^{-34}\left(\frac{\mathrm{kg} \cdot \mathrm{m}^{2}}{\mathrm{~s}}\right) \times 7.4 \times 10^{42}\left(\mathrm{~s}^{-1}\right)}{\left[0.299792458 \times 10^{9}\left(\frac{\mathrm{m}}{\mathrm{s}}\right)\right]^{2}} \\
& =5.455647929 \times 10^{-8}(\mathrm{~kg})
\end{aligned}
$$

Similarly, the remaining parameters of the gravitational field can be found.

Based on the found dependence (7), which makes it possible to apply the frequency oscillation $v_{G}=v_{U}$ when determining the constant $G(8)$ is associated with the gravitational field, as well as the constants $h(9)$ and $c(10)$ is associated with the electromagnetic field, the unity of these types of fields was strictly 
proved in 2019 [21] [22] [23], which was first substantiated in [24] [25] [26]:

$$
\begin{gathered}
\frac{G h v_{U}^{2}}{c^{5}}=1 \\
G=\frac{c^{5}}{v_{U}^{2} h} \\
h=\frac{c^{5}}{v_{U}^{2} G} \\
c=\sqrt[5]{v_{U}^{2} G h}
\end{gathered}
$$

Therefore we can assume a similarity in the shape and propagation of the waves of these fields, which allows us to replace the flat model of gravity (Figure 1(b) and Figure 3) on the volume, model (Figure 7).

In this model, waves of the gravitational field freely penetrate objects, because their length is many orders of magnitude less than the wave parameters of elementary particles, atoms and molecules that make up these objects. In this case, the penetration contradiction, insoluble for the circuit of Figure 4, is decided, and the concepts of "top" and "bottom" are automatically replaced by the directions of motion - to the center or from the center of mass of the object. The intensity and frequency of radiation of gravitational waves depend on the mass of objects.

In the found structure (Figure 7), secondary waves (moiré in the pictures) are visible from the superposition of the initial waves of the gravitational fields of two objects, which requires further research.

The new model of gravity on a rigorous scientific basis is justified by the actually existing laws of physics and leads to the establishment of previously unknown objectively existing laws, properties and phenomena of the material world that make fundamental changes in the level of scientific knowledge, which has all the signs of scientific discovery [27]. This paper does not deny the works on the curvature of space and can supplement them, which requires further research to coordinate them.

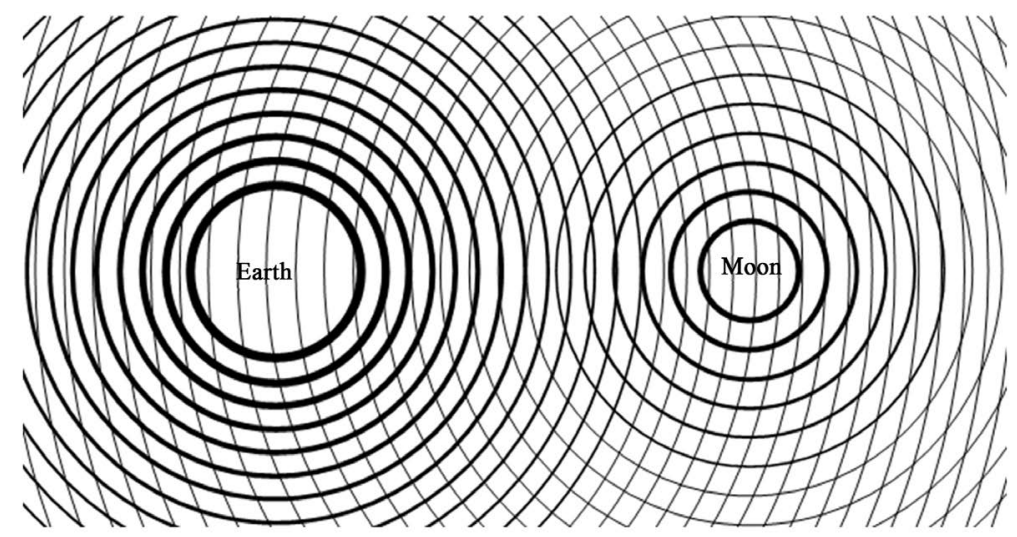

Figure 7. Spatial model of gravitational waves in the Earth-Moon system (diagram of the author of this work). 


\section{Conclusions}

1) Replacement in GRT of the gravity of the Universe by the curvature of its space leads to problems and contradictions in the interaction of any of its objects and their environment, in comparison with real processes that arise in such systems.

2) Well-known physical models explaining the processes of gravity based on the interaction of elastic membranes and objects located on them have significant drawbacks, the main of which is the need to switch from a flat system to a spatial one.

3) Mathematical models explaining the processes of gravity based on the curvature of flat surfaces also have significant shortcomings and contradictions, the main of which are: a) the need to transition from a flat system to a spatial one; b) the ambiguity of the formed curvature, the parameters of which do not correspond to real processes material world, since the finite quanta of space have no deformation and have finite dimensions.

4) The replacement of gravity with the curvature of space in general relativity played a positive role in the development of science of the 20th century, but at present it should be replaced by the theory of gravity based on wave laws and their parameters, which have three-dimensional spatial structure.

5) The proposed spatial-wave model of the action of gravity based on the wave parameters of the gravitational fields of material objects, in the framework of their unity with electromagnetic fields, reduces their structures to similar ones and eliminates the drawbacks of the previous model-of replaced gravity on curvature of space.

6) The new model processes of gravitating based on wave parameters of gravitational fields has a level of scientific discovery. Its use contributes to the development of science; it should be taken into account in further scientific research and in the teaching of the disciplines of physics in higher educational institutions, as well as adapting them in secondary specialized educational institutions and schools.

\section{Conflicts of Interest}

The author declares no conflicts of interest regarding the publication of this paper.

\section{References}

[1] Vasil'yev, V.V., Krotov, A.A. and Bugay, D.V. (2005) Istoriyafilosofii [History of Philosophy]. Akademicheskiy Proyekt, Moscow. (In Russian)

[2] Treder, G. (1970) Gravitacija [Gravitation]. Nauka i Chelovechestvo. Megdunarodnujejegodnik [Science and Humanity. International Yearbook]. Znanie, Moscow, 306-321. (In Russian)

[3] Alekseev, D.V., Bonch-Bruevich, A.M., Voronov-Romanov, A.S., et al. (1983) Phizicheskij encyclopedicheskij slovar [Physical Encyclopaedic Dictionary]. In: Prohorov, A.M., Ed., Pod Red, Sov. Encyclopedia, Moskow. (In Russian) 
[4] Eynshteyn, A. and Gravitatsii, T. (1979) Albert Einstein and the Theory of Gravity. Kuranskiy, Y.E. (red.), Mir, Moscow. (In Russian)

[5] Einstein A. (1916) Die Grundlage der allgemeinen Relativitätstheorie. Annalen der Physik, 354, 769-822. (Deutsch)

[6] Charl'z, M., Kip, T. and Dzhon, U. (1977) Gravitatsiya [Gravitation]. Mir, Moscow, T.1. (In Russian)

[7] Nastasenko, V. (2020) Analysis of the Processes of Gravity in the Framework of the Curvature of Space "Modern Science: Problems and Innovations". Abstracts of the 1st International Scientific and Practical Conference, Stockholm, 5-7 April 2020, 96-301.

http://sci-conf.com.ua/i-mezhdunarodnaya-nauchno-prakticheskaya-konferentsiya$\underline{\bmod -}$ ern-science-problems-and-innovations-5-7-aprelya-2020-goda-stokgolm-shvetsiyaarhiv/?utm_source=eSputnik-promo

[8] Nobel Prize in Physic (2017) Press Release: The Nobel Prize in Physics 2017. https://www.nobelprize.org/nobel_prizes/physics/laureates/2017/press.html

[9] Nastasenko, V.A. (2011) Novye Vozmozhnosti Analiticheskogo Utochneniya Velichiny Gravitatsionnoy Postoyannoy [New Opportunities for Analytical Refinement of the Gravitational Constant]. Naukoviy vísnik KHNTU: Naukoviy Zhurnal. KHNTU, Kherson, No. 4(43). (In Russian)

[10] Nastasenko, V.A. (2014) O Vozmozhnosty Opredelenyya Volnovykh Parametrov Hravytatsyonnoho Polya [On the Possibility of Determining the Wave Parameters of a Gravitational Field]. Visnyk Khersons'koho natsional'noho Tekhnichnoho Universytetu, KHNTU, Kherson, Vyp. 1(48), 71-76. (In Russian)

[11] Nastasenko, V.A. (2018) Discovery of Analytical Method Defined of Wave Parameters Gravitation Field. Journal of Lasers, Optics \& Photonics, 5.

[12] Fok, V.A. (1955) Teoriya Prostranstva, Vremeni i Tyagoteniya [Theory of Space, Time and Gravitation]. GITTL, Moscow, 504 s. (In Russian)

[13] Sing Dzh, L. (1963) Obshchaya Teoriya Otnositel'Nosti [General Theory of Relativity]. Internatsionalnaya Literatura, Moscow, 432 s. (In Russian)

[14] Alekseyev, G.N. (1978) Energiya i Entropiya [Energy and Entropy]. Znaniye, Moscow, 192 s. (In Russian)

[15] Nastasenko, V.A. (2019) Definition form and Parameters of Quantum of Space of the Universe. Journal Cosmological Astronomical Astrophysics, 1, 42-45. https://doi.org/10.18689/ijcaa-1000111

[16] Nastasenko, V.A. (2019) Refinement the Form and Parameters of Quantum of Space of the Universe. Journal Cosmological Astronomical Astrophysics, 1, 62-66. https://doi.org/10.18689/ijcaa-1000115

[17] Khramov, Y.A. (1983) Eynshteyn Al’bert, Fiziki: Biograficheskiy Spravochnik [Einstein Albert, Physicists: Biographical Reference]. Pod red. Akhiyezera, A.I., Izd. 2-ye, ispr. i dopoln, Nauka, Moscow, 400 s. (In Russian)

[18] Pauli, V. (1947) Obshchiye Printsipy Volnovoy Mekhaniki [General Principles of Wave Mechanics]. GITTL, Moscow, 332 s. (In Russian)

[19] (1993) Bibliya Ukrayins'koho Bibliynoho Tovarystva [Bible of the Ukrainian Bible Society]. Kyiv, 296 s. (In Ukraine)

[20] Committee on Data for Science and Technology. Internationally Recommended Values of the Fundamental Physical Constants.

https://physics.nist.gov/cuu/Constants/index.html 
[21] Nastasenko, V.A. (2018) Justification the Wave Oscillation Frequency of the Unified Field of the Universe. Astrophysics and Particle Physics 4th International Conference, Chicago, 3-5 December 2018, 62.

[22] Nastasenko, V.A. (2020) Novyye Dostizheniya v Oblasti Kvantovoy Fiziki [New Advances in Quantum Physics]. Science, Society, Education: Topical Issues and Development Prospects. Abstracts of the 2 nd International Scientific and Practical Conference, SPC "Sci-conf.com.ua", Kharkiv, 20-21 January 2020, 321-325. (In Russian)

http://sci-conf.com.ua/ii-mezhdunarodnaya-nauchno-prakticheskaya-konferencziy a-science-society-education-topical-issues-and-development-prospects-20-21-yanva rya-2020-goda-harkov-ukraina-arhiv/

[23] Nastasenko, V.A. (2020) 1-ye, 2-ye i 3-ye Kvantovo-Mekhanicheskiye Uravneniya V.A. Nastasenko i ikh Opredeleniye. Priority Directions of Science Development. Abstracts of the 5 th International Scientific and Practical Conference, SPC “Sci-conf.com.ua” Lviv, 2-3 March 2020, 276-280. (In Russian)

http://sci-conf.com.ua/v-mezhdunarodnaya-nauchno-prakticheskaya-konferentsiya -priority-directions-of-science-development-2-3-marta-2020-goda-lvov-ukraina-ar $\underline{\text { hiv/ }}$

[24] Nastasenko, V.A. (2014) Strohoe Opredelenye Volnovykh Parametrov Hravytatsyonnoho Polya y ob" Edynenye Hravytatsyonnoho y Élektromahnytnoho Poley [Strict Determination of the Wave Parameters of the Gravitational Field and the Union of Gravitational and Electromagnetic Fields]. Suchasni Informatsiyni ta Innovatsiyni Tekhnolohiyi na Transporti. Materialy Mizhnarodnoyi Naukovo-Praktychnoyi Konferentsiyi. KHDMA, Kherson, 198-204. (In Russian)

[25] Nastasenko, V.A. (2014) Novye Osnovy Dlya Strohoho Opredelenyya Volnovykh Parametrov Hravytatsyonnoho Polya y ob"Edynenye Hravytatsyonnoho y Élektromahnytnoho Poley [New Bases for Strict Determination of the Wave Parameters of the Gravitational Field and the Union of Gravitational and Electromagnetic Fields]. Naukovyy Visnyk KHDMA: Naukovyy Zhurnal, KHDMA, Kherson, 2014, No. 1, 213-222. (In Russian) http://kma.ks.ua/ua/images/science/publications/2014/1_10/31.pdf

[26] Nastasenko, V.A. (2017) Union of Gravitational and Electromagnetic Fields on the Basis of Nontraditional Principles. Electrical \& Computer Engineering, 6, 19-30. https://doi.org/10.14810/ecij.2017.6402

[27] (2003) Civiljniyjkodeks Ukrainu [Civil Code of Ukraine]. Zakonu Ukrainu. Shkola, Kyiv. (In Ukrainian) 